\title{
28. DOWNHOLE MEASUREMENTS AND PHYSICAL PROPERTIES, HOLE 735B: SUMMARY AND TECTONIC RELATIONSHIPS ${ }^{1}$
}

\author{
Richard P. Von Herzen, ${ }^{2}$ Henry J.B. Dick, ${ }^{2}$ and Paul T. Robinson ${ }^{3}$
}

\begin{abstract}
Extensive logging and special downhole measurements, described in chapters in this volume, are compared with laboratory physical properties from core samples to deduce the physical state of the 500 -m-thick gabbro section drilled at Site 735. Seismic, magnetic, electrical, thermal, and hydraulic downhole measurements provide relevant information about intrinsic rock properties, the distribution of fractures and permeability, and paleostress at this site on a slow-spreading $(\sim 1 \mathrm{~cm} / \mathrm{yr})$ ridge near a major fracture zone. The results comprise the first detailed physical characterization of a section thought to represent the lower oceanic crust.
\end{abstract}

\section{INTRODUCTION}

The unique results of Leg 118 drilling are emphasized in many other chapters of this volume. Leg 118 is the only ODP leg during which a significant vertical section of primarily gabbroic rocks was drilled and recovered (at Site 735). The high percentage of core recovery over much of the section $(>90 \%)$ is also unique for drilling of igneous rock in the world ocean. Most probably, the gabbroic rock drilled over this 500 -m-thick section is derived from an uplifted plutonic lower crustal section, and the $500-\mathrm{m}$ hole may represent a substantial thickness of this section, although we do not know how much of the lower crustal section at this site was penetrated. The relatively fresh condition of most of the recovered rock section implies that physical studies on the rocks will be useful for understanding their original condition after emplacement, taking into account the effects of subsequent cooling.

Because Leg 118 originally had been planned to drill mantle or lower crustal rocks that were emplaced near or at the surface in the Atlantis II Fracture Zone, we wished to investigate the physical properties of recovered samples and to acquire a broad suite of downhole logs. In addition to the array of standard logging tools available to ODP, special downhole tools, such as the borehole packer, vertical seismic profiling tool, three-axis magnetometers (and susceptibility tool), and high-resolution temperature tools had been acquired especially for this leg. This volume describes the results from these tools, almost all of which were successful because of a relatively clean Hole 735B and the excellent weather conditions for logging during Leg 118's last week at sea. This chapter summarizes some of the results that are described by other authors in this volume and includes relevant comparisons among the results of different experiments and measurements.

\section{COMPARISONS OF RELEVANT PHYSICAL PROPERTIES AND LOGS}

\section{Seismic Properties}

Some of the most useful and versatile correlations among physical properties and logs are those that employ acoustic or seismic methods. The different modes and wide range of

\footnotetext{
1 Von Herzen, R. P., Robinson, P. T., et al., 1991. Proc. ODP, Sci.
} Results, 118: College Station, TX, U.S.A (Ocean Drilling Program).

2 Woods Hole Oceanographic Institution, Woods Hole, MA 02543.

${ }^{3}$ Dalhousie University, Halifax, Nova Scotia B3H 3J5. frequencies used can provide a broad spectrum of deductions about relevant physical and chemical parameters for a given geological situation.

Several types of seismic studies were conducted in Hole $735 \mathrm{~B}$ and on the core retrieved. Downhole logs included a standard acoustic log, although the useful data retrieved were only partially complete, apparently the result of marginal signal levels over some depth ranges in the hole (Shipboard Scientific Party, 1989; Goldberg et al., this volume). However, the multichannel seismic tool gave satisfactory results over nearly the entire 500-m-depth range of the hole, and it is with these results that most of the core sample measurements are compared. Another major downhole seismic experiment was the vertical seismic profile (VSP) conducted near the end of Leg 118 (Swift, et al., this volume).

Seismic studies of core samples are of several different types. Shipboard investigations included measurements of seismic velocities, using the standard Hamilton Frame (Shipboard Scientific Party, 1989, p. 157). Some of these samples, especially those showing foliations and lineations, exhibited significant directional anisotropy, up to about $10 \%$. By employing this same Hamilton Frame, these samples were also used for a shipboard study of ultrasonic attenuation (Goldberg et al., this volume), and the relationship between attenuation and alteration was inferred.

Seismic studies at shore-based laboratories after the leg included additional velocity studies using samples that could not be measured at sea because of lack of time or because appropriate equipment did not exist aboard the drilling vessel. Itturino et al. (this volume) measured velocities for dry samples, under a range of hydrostatic pressures, to investigate the effects of crack closure in these samples. Combining these measurements and those from the shipboard samples with determinations of chemical composition, Itturino and Christensen (this volume) argue that the contents of $\mathrm{SiO}_{2}$ and $\mathrm{Fe}_{2} \mathrm{O}_{3}$ in the rock have an important effect on seismic velocities: greater amounts of either species in the rock bulk chemistry are systematically associated with lower seismic velocities. The experimental evidence is not clearcut about which of these chemical species is most important for controlling velocity, because they tend to co-vary inversely in amount for any given sample. Chemical composition most probably affects rock density, which Birch (1961) showed was the physical parameter most closely correlated with seismic velocity.

The major result of the shipboard VSP experiment (Swift et al., this volume) was that the overall seismic velocity through- 
out the depth of the hole in the vertical direction measured about $6.5 \mathrm{~km} / \mathrm{s}$, within the range expected for oceanic crustal layer 3 (Purdy and Ewing, 1986). In addition, post-cruise data processing showed significant seismic reflections at depths of about 50 to 70 and 200 to $250 \mathrm{mbsf}$. These depths may correlate, respectively, with near-surface zones of high porosity and with the high iron and titanium oxide zone found at these depths (Shipboard Scientific Party, 1989). Additional reflections at depths of about 560 and 760 to $825 \mathrm{mbsf}$, below the drilled section, are thought to be lithologic or structural interfaces in deeper crustal rocks, or transitions from crustal to upper mantle sections; additional seismic data and modeling will be required to confirm any of these interpretations.

An interesting feature of most of these reflections is that they were found at nearly constant time delays, with respect to the source event, for the range of in-hole receiver depths over which they were detected. For a uniform velocity section, a simple explanation is that the reflectors are approximately horizontal, at least in the vicinity of the hole location, because sloping reflectors should result in time delays that vary systematically with the depth of the in-hole receiver. However, at least for the depth ranges and velocities at Site 735 , modeling by Swift et al. (this volume) shows that arrival times from the reflectors are insensitive to their attitudes. The limited depth ranges over which the reflectors were received, and the lack of coherency of the waveforms over this range of receiver depths, are consistent with dips of up to $30^{\circ}$ to $40^{\circ}$. Therefore, one may not be able to correlate attitudes of any planar reflectors with structural elements determined from the recovered core.

As a result of comparing different seismic velocity data sets for Hole 735B, both in-situ and laboratory, S. Kirby et al. (unpubl. data, 1990) have postulated that the in-situ porosity of the drilled section may not be saturated. This hypothesis derives from their observations that velocities measured for shipboard saturated samples with the MCS downhole tool may be systematically greater than for the VSP experiment or for the dry samples measured in a shore-based laboratory. One infers that drilling at Hole 735B exposed these core samples and the rock surrounding the hole to high-pressure seawater, which quickly saturated the previously dry rock, with a corresponding increase in seismic velocity. However, it is not clear whether the velocities determined from these different data sets are significantly different, within the uncertainties of the various techniques employed. More careful measurements of samples, and additional downhole experiments with high accuracy, will be required to confirm this hypothesis.

We find it intuitively surprising that porosity would still be unsaturated 10 to $12 \mathrm{~m}$.y. after the rock formed from a magma, even if it were initially unsaturated upon solidification. Simple models may be used to estimate how rapidly fluid saturation might occur. For example, the time for a uniformly permeable layer of thickness, $L$, to be permeated by fluid after it has been exposed to the fluid on one side is given approximately by $T=$ $L^{2} / D$, where $D$ is the hydraulic diffusivity. The diffusivity is given by $D=k / P M C$, where $k$ and $P$ are the fluid permeability and porosity of the layer, respectively, and $M$ and $C$ are the dynamic viscosity and compressibility of the fluid, respectively. Using water as the fluid medium, these parameters may be estimated at Site 735 as follows:

$$
\begin{aligned}
& k \sim 10^{-16} \mathrm{~m}^{2} \text { (Becker, this volume), } P \sim 10^{-2}, \\
& M=1 \times 10^{-2} \text { poise }=1 \times 10^{-3} \mathrm{~kg} \mathrm{~m}^{-1} \mathrm{~s}^{-1}, \\
& C=5 \times 10^{-5} \mathrm{bar}^{-1}=5 \times 10^{-9} \mathrm{~kg}^{-1} \mathrm{~m} \mathrm{~s}^{2},
\end{aligned}
$$

so that we obtain $D=2 \times 10^{-3} \mathrm{~m}^{2} \mathrm{~s}^{-1}$ (Handbook of Chemistry and Physics, 1972). For a 500-m-thick layer, saturation by hydraulic diffusion from above takes only a few years, even using a low estimate for permeability, as measured by Becker (this volume).

Of course, the fluid permeability at Site 735 is probably not distributed homogeneously, but may be preferentially higher along cross-cutting fractures (see below). Water should then permeate quickly along any fractures that extend to the surface, but should take a long time to penetrate the solid rock between these fractures, depending on its intrinsic permeability. Although the fluid permeability of individual crystals can be extremely low, easier pathways for water probably would be along grain boundaries, where most of the porosity also probably exists (other than at fractures), as implied in the model of S. Kirby et al. (unpubl. data, 1990) for rapid saturation of the core and walls of the hole as a result of drilling.

The seismic anisotropy of many core samples from Hole $735 \mathrm{~B}$ was significant and systematically distributed with the rock fabrics (Shipboard Scientific Party, 1989). The velocities measured in directions parallel to the lineated and/or foliated fabrics, which were commonly found in the recovered core samples, average $5 \%$ to $10 \%$ higher than those measured perpendicular to these fabric directions. As already noted, this phenomenon has important implications for interpreting seismic experiments of oceanic crustal rock. In the situation of horizontally foliated rock fabrics, seismic refraction experiments (which usually measure velocities in the horizontal direction) would be expected to show higher values than VSP experiments (which measure vertical velocities). For Site 735, where the mean fabric and fracture foliations dip steeply, only small differences would be expected between horizontal and vertical velocities; however, Kirby et al. have found significant velocity differences between vertical and horizontal directions. A possible explanation is the presence of horizontally oriented microfractures that may have been created by uplift and unloading of the section at Site 735. Support for the existence of microfractures may be inferred (but not proven) from the laboratory velocity measurements of Iturrino et al. (this volume).

\section{Magnetic Properties}

Some of the magnetic properties of the rocks recovered from Hole 735B are unusual and interesting. Downhole magnetometer logs showed highly variable magnetic intensities and directions, as well as very high susceptibilities, especially in the zones characterized by a high proportion of irontitanium oxide minerals recovered in the cores. Laboratory magnetic measurements of the core samples confirmed the high values of natural remanent magnetization (NRM) and high susceptibility, especially in zones having significant magnetite and ilmenite. Extensive shipboard and shore-based measurements, summarized by Kikawa and Pariso (this volume), gave NRM intensities of up to $1.3 \times 10^{-1} \mathrm{emu} / \mathrm{cm}^{3}$, and susceptibilities of up to about $3.4 \times 10^{-2} \mathrm{cgs}$, very high values for rock thought to form the lower oceanic crust.

Kikawa and Pariso (this volume) measured 264 samples that exhibited NRM inclinations that were about equally divided between normal and reversed polarity. However, alternating field demagnetization in the laboratory gave nearly all samples a reversed stable inclination, which is consistent with the location of Site 735, and indicates that the NRM was probably acquired during a single reversed-polarity epoch of short duration ( $\sim 0.5 \mathrm{~m}$.y. or less). The thermal time constant for conductive cooling of a 5-km-thick crust is $\sim 1 \mathrm{~m} . \mathrm{y}$., and any hydrothermal circulation in the upper crust probably would reduce that time considerably. The unstable NRM component removed by alternating field cleaning was probably created during drilling and coring. The stable NRM of 
these rocks may contribute significantly to observed marine magnetic anomalies.

The average stable NRM of the samples measured from Leg 118 , about $1.6 \times 10^{-3} \mathrm{emu} / \mathrm{cm}^{3}$, would provide approximatly the amplitude of magnetic anomalies observed at the sea surface $(+/-100 \mathrm{nT})$, if distributed uniformly throughout a 4to $5-\mathrm{km}$-thick ocean crustal layer 3 , without considering any contribution of the upper crustal magnetization to the anomalies. The amplitude of the magnetic anomalies actually measured during the site survey conducted in preparation for drilling the Atlantis II Fracture Zone (Dick et al., this volume) range up to several hundred or more nannoteslas in amplitude, which might be explained by comparable contributions from upper, as well as lower, crustal rock magnetized in the Earth's magnetic field.

Another important observation by Kikawa and Pariso, which confirms other studies elsewhere, is that the NRM intensity of the rock samples does not correlate with the extent of their alteration, based on the amount of secondary hydrous minerals. It seems surprising that the intensity of magnetization is apparently not significantly affected by the amount of alteration in the rock.

Cannat and Pariso (this volume) have used the magnetic measurements of samples to obtain information about the orientation of associated rock fabrics referenced to Earth's magnetic field. The directions of the dip of the ductily formed lineations and foliations are reasonably consistent throughout the drilled section and range from about $240^{\circ}$ to $340^{\circ}$ in azimuth, with respect to the stable remanent magnetic vector. In contrast, vein orientations generally have dip azimuths opposite those of the deformational fabrics. Since the stable remanent magnetism of the rocks drilled at this site is reversed from that of the present field throughout the section (Kikawa and Pariso, Pariso et al., this volume), such that the magnetic reference vector azimuth may be assumed to point south, the deformational fabrics would have a generally eastward dip, and the veins generally westward. This vein dip direction is generally the same as the macrofracture dip direction observed in situ using the borehole televiewer (Goldberg et al., this volume).

\section{Electrical Properties}

The electrical resistivities of 29 core samples were determined in the laboratory by Pezard et al. (this volume). The lowest measured resistivities $(\sim 40 \mathrm{ohm}-\mathrm{m})$ are almost certainly the result of low mineral resistivity in samples having an elevated iron- and titanium-oxide composition and correlate spatially in the hole with low logged resistivities $(<10 \mathrm{ohm}-\mathrm{m})$. However, the range of variation in the samples is about one order of magnitude less than that determined from logging. This might be caused by the limited number of samples, such that the true range of rock resistivity is not represented in the samples selected, or there might be a spatial correlation of low resistivity samples with high porosity, which would combine to enhance the total effect in-situ. The latter possibility is not obvious in the data from Hole 735B. For example, the highest porosity spikes derived from the logging data (Goldberg et al., this volume) are from the uppermost 150 mbsf of the hole, whereas no samples from this zone have intrinsic low resistivity.

Some discrepancies may exist in the quantitative comparisons of porosity with the electrical resistivity derived from logging data. For example, in the uppermost $100 \mathrm{~m}$ of the hole, the corrected porosity spikes reach porosity values $(P)$ as high as $P=20 \%$. Assuming that seawater is the pore fluid and that Archie's law $\left(R=R_{w} \times P^{-2}\right.$, where $R_{w}=0.25 \mathrm{ohm}-\mathrm{m}$, seawater resistivity) expresses the effect of porosity on the resistivity, $R$, the calculated resistivity is about 6 ohm-m for such high-porosity zones. These porosity values have been corrected from other logs for the effects of rock alteration, which can sometimes give an apparent porosity in these zones that is nearly twice as large, or about $40 \%$; if one assumes that alteration has an effect similar to seawater porosity, the expected resistivity should be $<2$ ohm-m. In comparison, the lowest resistivities are about $40 \mathrm{ohm}-\mathrm{m}$, as measured by the laterolog (shallow or deep), and as low as $8 \mathrm{ohm}-\mathrm{m}$, when measured by the induction log, over the upper part of the hole (Shipboard Scientific Party, 1989, Fig. 78). The laterolog values are probably severely biased for such low resistivities (Schlumberger, 1972), whereas the induction logging tools, which are better designed for low resistivities, are probably reasonably accurate. Therefore one can see that the resistivities measured by the induction tool are reasonably consistent with the corrected porosities values. This comparison suggests that the resistivities measured by the induction tool in the high iron-titanium oxide zone (as low as $3 \mathrm{ohm}-\mathrm{m}$ ) are also accurate, even though no core samples having such low resistivities were measured.

\section{Comparison of Logs}

Some of the comparisons among different logs presented by Goldberg et al. (this volume) permit some assessment of the validity of deductions that may be made from individual logs in comparable geological environments. The borehole televiewer $\log$ showed about 70 macrofractures striking generally north to northwest, with a steep dip $\left(>30^{\circ}\right)$ to the west or southwest, over the $500 \mathrm{~m}$ depth of the hole. Although this strike direction is comparable to the general strike direction of the planar fabrics, as deduced by Cannat and Pariso (this volume), the mean dip of the deformational fabrics (eastward) is opposite to that of the veins (westward). The stress field probably changed during the geological history of Site 735 , between the time when high-temperature deformation created the deformational fabrics and the time at which the fractures and veins were formed. The veins apparently have shallower mean dips than the fractures. Goldberg et al. suggest that at least the fractures were caused by uplift (rather than northsouth plate motion) at the site.

Goldberg et al. also note that the borehole televiewer showed no evidence for borehole breakouts, which implies that at present no significant overall deviatoric stress field exists at the site. However, during core splitting, the deviation of some core halves along saw cuts indicated local (centimeter to meter scale) stress inhomogeneities, perhaps stored in the rock from the cooling of anisotropic or irregularly packed mineral grains having different expansion coefficients.

The pulsed neutron log, which is sensitive to the in-situ hydrogen content of the rock, was useful for comparison with the porosities of measured samples. For sections where discrete fractures having significant porosity were not present, this comparison allowed one to estimate the rock alteration, based on the assumption that alteration adds hydroxyl ions. In most cases, neutron porosities (uncorrected) were larger than those determined for samples, as expected.

Temperature logs (Von Herzen and Scott, this volume) were useful for showing anomalies in the hole temperature gradient that were interpreted as permeable fractures or zones intersected by the hole. In addition, the MCS log showed semblance anomalies, associated with porous or permeable zones (Goldberg et al., this volume). Their locations are consistent with the permeability structure deduced by Becker (this volume) from packer experiments. The implications of these logs are (1) that the permeability in the section at this site is localized over a few small zones (fractures?) that 
intersect the hole, but (2) that most of the rock is relatively impermeable, as would be consistent with its overall low porosity.

\section{CONCLUSIONS}

The wide variety of downhole measurements and physical properties measured on core samples in the laboratory have characterized the in-situ physical state of the primarily gabbro section at Site 735 as well as parts of its geological history. Although our understanding is still incomplete, these measurements have provided valuable information about three general topics:

1. The vertical distribution of in-situ fractures and permeability. Macrofractures that affect physical properties (e.g., porosity) of in-situ rock are common in the uppermost 100 mbsf, and decrease markedly below this depth, as deduced from neutron logs. Corroborative evidence for this fracture distribution has been provided most directly by sonic (MCS) logs and the borehole televiewer. Borehole packer experiments show clear evidence for decreasing fluid permeability with depth by at least two orders of magnitude from the seafloor to $500 \mathrm{mbsf}$. Temperature gradient anomalies suggest that permeable zones are localized in discrete depths in the hole, rather than being distributed over all macrofractures.

2. Intrinsic rock properties of oceanic gabbros. Seismic, magnetic, and electrical properties were determined in-situ, as well as on core samples in the laboratory. Mean vertical seismic velocities determined on samples are $\sim 6.5 \mathrm{~km} / \mathrm{s}$, comparable to the mean velocity determined from the VSP experiment over the entire $500-\mathrm{m}$ vertical section. Most samples show significant directional anisotropy ( $~ 5 \%-10 \%)$ that is controlled by the rock fabric. Ultrasonic $(400 \mathrm{kHz})$ attenuation may reflect rock alteration, as determined from correlation with hydrated mineral contents. Interestingly, remanent magnetic intensities and susceptibilities, reaching very high values in the iron-titanium oxide gabbros, do not appear to correlate with rock alteration; the lower oceanic crust may be a significant contributor to marine magnetic anomalies. The iron-titanium oxide gabbros also exhibit very low values of electrical resistivity $(<10 \mathrm{ohm}-\mathrm{m})$; the lowest in-situ values determined from induction logging, even lower than those measured in samples in the laboratory, are intrinsic because the porosity in this interval is also very low (mean $<5 \%$ ).

3. Stress. Evidence for paleostress and its probable directional variation with geological time is derived from comparison of the rock fabrics and fractures. The deformational fabrics generally dip steeply to the east, whereas the fractures and veins dip to the west. Deformational fabrics indicate significant high-temperature shear strain that is locally distributed in zones over centimeter to meter scales; the macrofractures and veins dipping in an orthogonal direction may have formed later in a different stress field. The lack of significant borehole breakouts indicates only minimal, if any, deviatoric stress presently at Site 735 .

\section{ACKNOWLEDGMENTS}

We are indebted to the other members of the scientific party for discussion and for the papers which contributed to this summary; and to the ODP technical group, the ship's officers, crew, and drilling personnel aboard Leg 118, all of whom assisted in obtaining the measurements discussed in this chapter. The first author appreciates input and advice from K. Becker about estimating hydraulic diffusivity.

\section{REFERENCES}

Birch, F., 1961. The velocity of compressional waves in rocks to 10 kilobars, 2. J. Geophys. Res., 66:2199-2224.

Handbook of Chemistry and Physics, 1972: New York (CRC Press), Weast, R. (Ed.), F-5 and F-36.

Purdy, G. M., and Ewing, J., 1986. Seismic structure of the ocean crust. In Vogt, P., and Tucholke, B. (Eds.), The Geology of North America, Vol. M, The Western North Atlantic Region: Boulder (Geol. Soc. Am.), 313-330.

Schlumberger, 1972. Log Interpretation, Vol. 1-Principles: Houston (Schlumberger, Inc.).

Shipboard Scientific Party, 1989. Site 735. In Robinson, P. T., Von Herzen, R., et al., Proc. ODP, Init. Repts., 118: College Station, TX (Ocean Drilling Program), 89-222.

Date of initial receipt: 27 February 1990

Date of acceptance: 21 June 1990

Ms 118B-165 